\title{
Trypanosoma cruzi Neurotrophic Factor Facilitates Cardiac Repair in a Mouse Model of Chronic Chagas Disease
}

\author{
Tamar Ledoux, Daniel Aridgides, Ryan Salvador, Njabulo Ngwenyama, Smaro Panagiotidou, \\ Pilar Alcaide, Robert M Blanton, and Mercio A Perrin
}

Program in Pharmacology and Experimental Therapeutics (T.L., S.P., M.P.) and Program in Immunology (D.A., R.S., N.N., P.A.), Sackler School of Graduate Biomedical Sciences and Departments of Developmental, Molecular and Chemical Biology (T.L., D.A., R.S., S.P., M.P.) and Immunology (N.N., P.A.), Tufts University, Boston, Massachusetts; and Molecular Cardiology Research Institute and Division of Cardiology (R.B.), Tufts Medical Center, Boston, Massachusetts

Received July 6, 2018; accepted October 18, 2018

\begin{abstract}
Most patients acutely infected with Trypanosoma cruzi undergo short-term structural and functional cardiac alterations that heal without sequelae. By contrast, in patients whose disease progresses to chronic infection, irreversible degenerative chronic Chagas cardiomyopathy (CCC) may develop. To account for the contrast between cardiac regeneration in high-parasitism acute infection and progressive cardiomyopathy in low-parasitism CCC, we hypothesized that $T$. cruzi expresses repair factors that directly facilitate cardiac regeneration. We investigated, as one such repair factor, the T. cruzi parasite-derived neurotrophic factor (PDNF), known to trigger survival of cardiac myocytes and fibroblasts and upregulate chemokine chemokine $\mathrm{C}-\mathrm{C}$ motif ligand 2, which promotes migration of regenerative cardiac progenitor cells (CPCs). Using in vivo and in vitro models of Chagas disease, we tested whether $T$. cruzi PDNF promotes cardiac repair.
\end{abstract}

Quantitative PCR and flow cytometry of heart tissue revealed that stem-cell antigen-1 (Sca- $\left.1^{+}\right)$CPCs expand in acute infection in parallel to parasitism. Recombinant PDNF induced survival and expansion of ex vivo CPCs, and intravenous administration of PDNF into naïve mice upregulated mRNA of cardiac stem-cell marker Sca-1. Furthermore, in CCC mice, a 3-week intravenous administration of PDNF protocol induced CPC expansion and reversed left ventricular T-cell accumulation and cardiac remodeling including fibrosis. Compared with CCC vehicle-treated mice, which developed severe atrioventricular block, PDNF-treated mice exhibited reduced frequency and severity of conduction abnormalities. Our findings are in support of the novel concept that $T$. cruzi uses PDNF to promote mutually beneficial cardiac repair in Chagas disease. This could indicate a possible path to prevention or treatment of CCC.

\section{Introduction}

Trypanosoma cruzi is the causative agent of incurable Chagas disease, which is endemic in Latin America and estimated by the Centers for Disease Control and Prevention to afflict more than 8 million people worldwide (www.CDC.gov). Acute $T$. cruzi infection initially induces structural and functional cardiac alterations, such as cardiomegaly, focal inflammation, and conduction abnormalities, that heal without sequelae in $>95 \%$ of patients (Parada et al., 1997). The chronic phase of Chagas disease, defined by extremely low parasite burden, is classified into two phases: indeterminate, in which patients do not display pathology or symptoms, and symptomatic, resulting from tissue degeneration in the heart (chronic Chagas cardiomyopathy, CCC) and/or gastrointestinal tract

This work was supported by the National Institutes of Health [Grants R01 AI113075, AI09738] to M.P. Primary laboratory of origin: M.P., T.L., D.A., R.S. S.P

https://doi.org/10.1124/jpet.118.251900. abnormalities (megaesophagus and megacolon) years or decades after the onset of acute infection (Dias et al., 1956; Köberle, 1968; Prata, 2001; Rassi et al., 2010; Nunes et al., 2013; Bern, 2015). Approximately $30 \%$ of Chagasic patients in the indeterminate phase progress to CCC, which is also characterized by cardiac remodeling that includes fibrosis, a robust inflammatory response, and structural/functional alterations such as atrioventricular (AV) block (Dias et al., 1956; Köberle, 1968; Rassi et al., 2010; Nunes et al., 2013; Pérez-Molina and Molina, 2018). Tissue damage in CCC progresses inexorably, often leading to heart failure and death. No pharmacologic treatments are currently available to prevent or treat progression of CCC (Paucar et al., 2016).

Several mechanisms have been proposed to explain the paradox that pathology in CCC, unlike in acute infection, occurs despite scarcity of parasites (Marin-Neto et al., 2007). One hypothesis suggests that inflammation results from the autoimmune crossreaction of specific anti-T. cruzi immune responses with host antigens such as cardiac myosin (Cunha-Neto and Kalil, 1995; Cunha-Neto et al., 1996). However, autoimmune

ABBREVIATIONS: AV, atrioventricular; CCC, chronic Chagas cardiomyopathy; CPC, cardiac progenitor cell; DAB, [1,1'-biphenyl]-3,3',4,4'tetramine; ECG, electrocardiogram; FBS, fetal bovine serum; IHC, immunohistochemistry; LV, left ventricle; PBS, phosphate-buffered saline; PCR, polymerase chain reaction; PDNF, parasite-derived neurotrophic factor; PFA, paraformaldehyde; PI, postinfection; Sca-1, stem cell antigen-1; sPDNF, short-form parasite-derived neurotrophic factor; Uninf, uninfected controls. 
responses also occur in acute infection and pathology-free indeterminate disease (Prata, 2001; Lu et al., 2008, 2010; Rassi et al., 2010). Another possible explanation is that tissue degeneration in CCC represents collateral damage from the strong immune response to lingering cardiac parasitism (Ben YounèsChennoufi et al., 1988; Bellotti et al., 1996; Tarleton and Zhang, 1999; Pérez-Molina and Molina, 2018). Parasite load measurements quantified by real-time PCR, however, did not detect differences in parasitemia in patients presenting with indeterminate, cardiac, or digestive clinical manifestations (Melo et al., 2015). In addition, the extent of $T$. cruzi antigens in human hearts with CCC did not correlate with the intensity of histopathological lesions (Palomino et al., 2000). Therefore, although these mechanisms all probably contribute to CCC pathogenesis (Machado et al., 2012), additional mechanisms of CCC development remain poorly understood and, if elucidated, may provide novel therapeutic strategies for this condition.

The present study investigates the alternative hypothesis that cardiac dysfunction, remodeling, and cardiomyopathy in chronic Chagas disease are linked to low heart parasitism as opposed to the relatively high parasite burden in acute infection. This hypothesis would have credence if $T$. cruzi were to express an agent(s) capable of mediating cardiac repair. We investigated the potential role of parasite-derived neurotrophic factor (PDNF) in modulating CCC progression.

PDNF, a T. cruzi outer membrane, glycophosphatidylinositolanchored protein, was originally identified in our laboratory as a neuraminidase (Pereira, 1983). Subsequently, PDNF was found to also transfer sialyl residues from exogenous glycoconjugates to T. cruzi $\beta$-galactosyl acceptors (Previato et al., $1985)$; this additional enzymatic activity resulted in a second designation for the neuraminidase as a trans-sialidase (Parodi et al., 1992; Schenkman et al., 1992; Scudder et al., 1993). Further studies revealed that PDNF additionally stimulates survival pathways in a number of cell types, independent of sialic acid-binding activities (Chuenkova and Pereira, 2000), and that it does so by binding and activating TrkA and TrkC, both neurotrophic receptor tyrosine kinases (Chuenkova and PereiraPerrin, 2004; Weinkauf et al., 2011). For this reason, we also call the neuraminidase/trans-sialidase parasite-derived neurotrophic factor to designate it as having survival-related biologic activities (Chuenkova and Pereira, 2003). The short-form of PDNF (sPDNF) used in this study is a recombinant, bacterially expressed $\mathrm{N}$-terminal domain of the protein lacking the $\mathrm{C}$-terminal tandem repeat (Chuenkova et al., 1999; Chuenkova and Pereira, 2000; de Melo-Jorge and PereiraPerrin, 2007; Weinkauf et al., 2011; Aridgides et al., 2013a; Salvador et al., 2014).

We have previously shown that PDNF promotes survival of cardiac myocytes and fibroblasts (Aridgides et al., 2013a,b; Salvador et al., 2014), suggesting that PDNF may have cardiac regenerative effects. Additionally, we have shown that intravenous PDNF upregulates the expression of chemokine C-C motif ligand 2 (Salvador et al., 2014), also known as monocyte chemoattractant protein-1 (MCP-1), a cardioprotective chemokine that modulates the myocardial stress response to reduce damage and facilitate repair in ischemia/reperfusion (Niu and Kolattukudy, 2009). MCP-1 also induces migration of cardiac stem cells to injury sites following myocardial infarction, and may contribute to the regeneration of wounded cardiac tissues (Tamura et al., 2011). Based on the action of sPDNF on cardiac cells and its upregulation of a chemokine that drives cardiac progenitor cell (CPC) expansion, we propose that this $T$. cruzi protein is one novel mechanism that facilitates parasite-mediated cardiac repair.

Accordingly, we observe that sPDNF stimulates the expansion of CPCs identified by the stem-cell marker stem-cell antigen-1 (Sca-1). Furthermore, PDNF drives attenuation of cardiac remodeling and dysfunction in a mouse model of CCC: Mice injected with intravenous recombinant PDNF exhibit reduced hypertrophy, a significant improvement in fibrosis, and substantially reduced severity of AV block. The study findings raise the possibility that this mechanism could constitute a path to an effective treatment option for CCC.

\section{Methods}

Ethics Statement. All mouse work was carried out in accordance with the Guide for the Care and Use of Laboratory Animals as adopted by the National Institutes of Health, and was approved by the Institutional Animal Care and Use Committee of Tufts University School of Medicine and Division of Laboratory Animal Medicine.

Parasites. T. cruzi Colombian strain were harvested from Vero cells (ATCC, Manassas, VA), as previously described (Chuenkova and PereiraPerrin, 2004). Trypomastigotes were collected from culture supernatant and purified by differential centrifugation, then resuspended in appropriate media [phosphate-buffered saline (PBS) or respective cell culture medium for in vivo and in vitro applications, respectively].

Acute T. cruzi Infection. Eight-week-old female C57BL/6J mice (Jackson Laboratory, Bar Harbor, ME) were infected with 1000-3000 parasites by intravenous tail vein injection. Mice were euthanized at the peak of acute infection, 18-20 days postinfection (PI), or at the indicated timepoint.

Quantitative Polymerase Chain Reaction. mRNA was isolated from QIAzol (Qiagen, Hilden, Germany) lysates of flash-frozen tissue samples mechanically dissociated using a Tissue Tearor (Biospec Products, Inc., Bartlesville, OK) per manufacturer protocol. cDNA was synthesized using QuantiTect Reverse Transcription Kit (Qiagen) per manufacturer protocol. Gene transcripts were quantified after amplification using specific primers and SYBR green (Qiagen), and normalization to housekeeping gene hypoxanthine-guanine phosphoribosyltransferase.

Flow Cytometry. Mouse hearts were digested with collagenase type II $(0.895 \mathrm{mg} / \mathrm{ml})$ (Worthington Biochemical, Lakewood, NJ) and protease XIV $(0.5 \mathrm{mg} / \mathrm{ml}$, except for Sca-1 experiments) (MilliporeSigma, St. Louis, MO), and cells were surface-stained with the following monoclonal antibodies: FITC-conjugated $\alpha$-Sca-1 (D7) (Miltenyi Biotec, Bergisch Gladbach, Germany), FITC-conjugated $\alpha$-CD3e (145-2C11), PE-conjugated $\alpha$-CD45.2 (104), APC-Cy7-conjugated $\alpha$-Ly-6C (HK1.4), PerCP-conjugated $\alpha$-CD11b (M1/70) (BioLegend, San Diego, CA), as previously described (Nevers et al., 2017). Antibodies were diluted in PBS plus $2 \%$ fetal bovine serum (FBS) and incubated with cells for 20 minutes at room temperature. After two washes in PBS plus $2 \% \mathrm{FBS}$, cells were run and data acquired on an LSR II (BD Biosciences, Franklin Lakes, NJ) and analyzed using FlowJo software (Ashland, OR).

Isolation of Sca-1 ${ }^{+}$CPCs. Sca- $1^{+}$CPCs were isolated from the hearts of $\mathrm{C} 57 \mathrm{Bl} / 6 \mathrm{~J}$ mice. Blood was removed from the heart post mortem with a 27-guage 1-ml insulin syringe. The heart was perfused with cold PBS, then excised, cut transversely in half and placed in icecold Hank's buffered salt solution (Gibco/Thermo Fisher Scientific, Waltham, MA) with 10,000 IU/ml Collagenase II (Worthington Biochemical). Tissue was homogenized using the gentleMACS Dissociator (Miltenyi Biotec) per manufacturer protocol. Red blood cells were lysed using Red Blood Cell Lysis Buffer (MilliporeSigma), and remaining cells were washed in autoMACS Running Buffer (Miltenyi Biotec) to create single-cell suspensions. Sca- $1^{+}$CPCs were then 
magnetically labeled and isolated using the Anti-Sca-1-MicroBead Kit (FITC) (Miltenyi Biotec) per manufacturer protocol. Cells were seeded in a six-well plate in duplicate in enriched medium and incubated at $37^{\circ} \mathrm{C} / 5 \% \mathrm{CO}_{2}$.

Differentiation and Clonogenicity Experiments. Sca- $1^{+}$cells were plated in either basal medium (Iscove's modified Dulbecco's medium $/ 10 \%$ FBS) or medium containing $20 \mathrm{ng} / \mathrm{ml}$ of vascular endothelial growth factor (VEGF) to induce differentiation into an endothelial cell phenotype. After 14 days, cells were fixed and stained with $\alpha$-von Willebrand factor ( $\alpha$-vWF) (1:100; Agilent/Dako, Santa Clara, CA) followed by Alexa 594-conjugated $\alpha$-rabbit IgG secondary antibody (1:500; Molecular Probes, Eugene, OR). Cells were counterstained with DAPI. Images were captured using the same exposure times and were processed in a similar manner. For differentiation into cardiomyocytes, cells were plated in basal media or media containing $10 \mathrm{mM} 5$-azacytidine for 3 days, then basal media for 14 days. Cells were fixed and stained with $\alpha$-Myosin Heavy Chain $(\alpha$-MyHC) (1:100; MilliporeSigma, Burlington, MA) followed by Alexa 568-conjugated $\alpha$-mouse IgG secondary antibody (1:500; Molecular Probes). To assess clonogenicity, Sca-1+ cells were cloned into 96 -well plates by limiting dilution ( 0.5 cells/well, verified by microscopy) and grown in Dulbecco's modified Eagle's medium/10\% FBS. Cell colonies could be detected after 2 weeks in culture; after 4 weeks, colonies were fixed, stained with Diff-Quik (Thermo Fisher Scientific) or $\alpha$-Sca-1 followed by fluorescence-labeled secondary antibody, and imaged.

sPDNF Purification. sPDNF was cloned into BL21 expression bacteria and purified by Ni-affinity chromatography, as previously described (Chuenkova et al., 1999; Chuenkova and Pereira, 2003; Weinkauf et al., 2011). Protein was buffer-exchanged into PBS and quantified by BCA assay (Thermo Fisher Scientific) per manufacturer protocol. sPDNF was stored at $4^{\circ} \mathrm{C}$ for short-term use ( $\leq 1$ month) and at $-80^{\circ} \mathrm{C}$ for long-term use ( $>1$ month).

Cumulative Growth Curves. CPCs were seeded at known density in basal medium or medium containing $4 \mu \mathrm{g} / \mathrm{ml} \mathrm{sPDNF}$, then incubated at $37^{\circ} \mathrm{C} / 5 \% \mathrm{CO}_{2}$ until nearly $100 \%$ confluent. Cell counts were recorded with each passage, and cumulative growth was calculated by multiplying the number of seeded cells by the multiplicity exhibited during the growth period (usually 1 week).

Oxidative Stress Test. CPCs were plated in CPC medium overnight and pretreated with $300 \mathrm{ng} / \mathrm{ml} \mathrm{sPDNF}\left(+\mathrm{sPDNF}+\mathrm{H}_{2} \mathrm{O}_{2}\right)$ or PBS vehicle $\left(+\mathrm{H}_{2} \mathrm{O}_{2}\right)$ for 30 minutes before incubation with $1.25 \mathrm{mM} \mathrm{H}_{2} \mathrm{O}_{2}$ or PBS vehicle (Vehicle) for 3.5 hours. Percentage cell death was assessed by propidium iodide/Hoechst, as previously described (Chuenkova et al., 2001; Chuenkova and PereiraPerrin, 2004).

Chronic Chagas Cardiomyopathy Mouse Model. We used the mouse model of CCC described earlier by the Ribeiro-dos Santos group (Soares et al., 2004): Female C57BL/6J mice, 8-week-old, were infected with Colombian T. cruzi (3000 parasites by IP injection or 1000 by IV injection); age-matched controls (Uninf) were injected with PBS only. Five months PI, mice were injected with $25 \mu \mathrm{g}(\sim 3 \mathrm{mg} / \mathrm{kg}) \mathrm{IV}$
sPDNF (CCC-sPDNF) or $200 \mu$ l PBS vehicle (CCC-Veh) at $T=0,3$, and 24 hours weekly for 3 weeks. Euthanasia and harvest occurred 8 weeks after the final injection.

Immunohistochemistry. Mouse left ventricles (LVs) were fixed in 4\% paraformaldehyde (PFA) for 24-48 hours, then submitted to Tufts' Histology Core for sectioning and staining. LVs were cut into crosssections, then stained with $\alpha$-CD4 or $\alpha$-CD8 (eBiosciences/Thermo Fisher Scientific) followed by biotinylated secondary antibody, streptavidin $H R P$, and DAB visualization. Images $(20 \times, 9-11$ per section $)$ were captured and overlaid with a grid in ImageJ. Fields positive for CD4/ CD8 staining were calculated as a percent of all fields in the grid.

Heart Weight. After mice were euthanized, hearts were excised and weighed. Heart weight was normalized to tibia length measured post mortem to the nearest $0.1 \mathrm{~mm}$ with a digital caliper (Fisher Scientific, Hampton, NH).

Transthoracic Echocardiography with Electrocardiogram. Echocardiography was performed at various intervals over the course of the chronic infection, including prior to sPDNF treatment, 4 weeks after treatment, and 8 weeks after treatment just prior to euthanasia. Echocardiography with limb-lead electrocardiogram was performed on a Vevo 2100 imaging system (VisualSonics, Toronto, ON, Canada) under light sedation with $2.5 \%$ isoflurane by a blinded investigator. M-mode and two-dimensional images were obtained from the shortaxis view, as described earlier (Blanton et al., 2012). LV end-diastolic and end-systolic diameters were measured by averaging values from at least five cardiac cycles.

Cardiomyocyte Cross-Sectional Area. Mouse LVs were fixed in 4\% PFA for 24-48 hours, then submitted to Tufts' Histology Core for sectioning and staining. LVs were cut into cross-sections, then stained with hematoxylin and eosin. Cardiomyocytes which were identified as round cells with central nuclei were measured for area using SPOT Advanced software (SPOT Imaging/Diagnostic Instruments, Inc., Sterling Heights, MI).

Fibrosis. Mouse LVs were fixed in 4\% PFA for 24-48 hours, then submitted to Tufts' Histology Core for sectioning and staining. LVs were cut into cross-sections, and then stained with Sirius Red (stains collagens) and Fast Green (stains noncollagenous proteins) for highcontrast visualization of fibrotic tissue. Whole-section stitched images at $10 \times$ magnification were captured on a Keyence BZ-X and then used to quantify percent fibrosis with BZ-X Analyzer (KEYENCE, Osaka, Japan). All images were captured at the same time using similar settings and were batch processed for uniform analysis.

Statistics. For comparison between two groups, we used unpaired $t$ tests. For comparison between three or more groups, we used oneway analysis of variance with Tukey's post-hoc test. For ejectionfraction (EF) and fractional-shortening (FS) data (Table 1), which were not normally distributed, we used the nonparametric KruskalWallis test. Data are expressed as the mean \pm S.D. unless otherwise noted, and $P$ values $<0.05$ were considered statistically significant. All data were analyzed in GraphPad Prism (GraphPad, La Jolla, CA).

TABLE 1

Echocardiography for CCC mice

Uninf, $n=9$; CCC-Veh, $n=8$; CCC-sPDNF, $n=10$. Mean + S.D. is indicated for each parameter.

\begin{tabular}{lccc}
\hline & Uninf & CCC-Veh & CCC-sPDNF \\
\hline End diastolic diameter (mm) & $3.637 \pm 0.30$ & $4.629 \pm 1.03^{a}$ & $3.489 \pm 0.49^{b}$ \\
End systolic diameter (mm) & $2.620 \pm 0.43$ & $3.233 \pm 1.06$ & $2.142 \pm 0.55^{b}$ \\
Anterior wall thickness (mm) & $0.780 \pm 0.13$ & $0.771 \pm 0.19$ & $0.776 \pm 0.10$ \\
Posterior wall thickness (mm) & $0.879 \pm 0.20$ & $0.864 \pm 0.27$ & $0.872 \pm 0.25$ \\
Heart rate (bpm) & $438.9 \pm 52.4$ & $226.3 \pm 124.2^{c}$ & $58.59 \pm 11.05$ \\
Ejection fraction (\%) & $54.58 \pm 12.26$ & $31.20 \pm 6.72$ & $347.8 \pm 131.0$ \\
Fractional shortening (\%) & $28.24 \pm 8.35$ & $164.98 \pm 89.04$ & $39.13 \pm 12.06$ \\
LV mass (mg) & $106.23 \pm 22.57$ & & $97.96 \pm 22.54^{d}$ \\
\hline
\end{tabular}

bpm, beats per minute.

${ }^{a} P<0.05$, Uninf vs. CCC-Veh.

${ }^{b} P<0.01$, CCC-Veh vs. CCC-sPDNF.

${ }^{c} P<0.01$, Uninf vs. CCC-Veh;

${ }^{d} P<0.05$, CCC-Veh vs. CCC-sPDNF. 

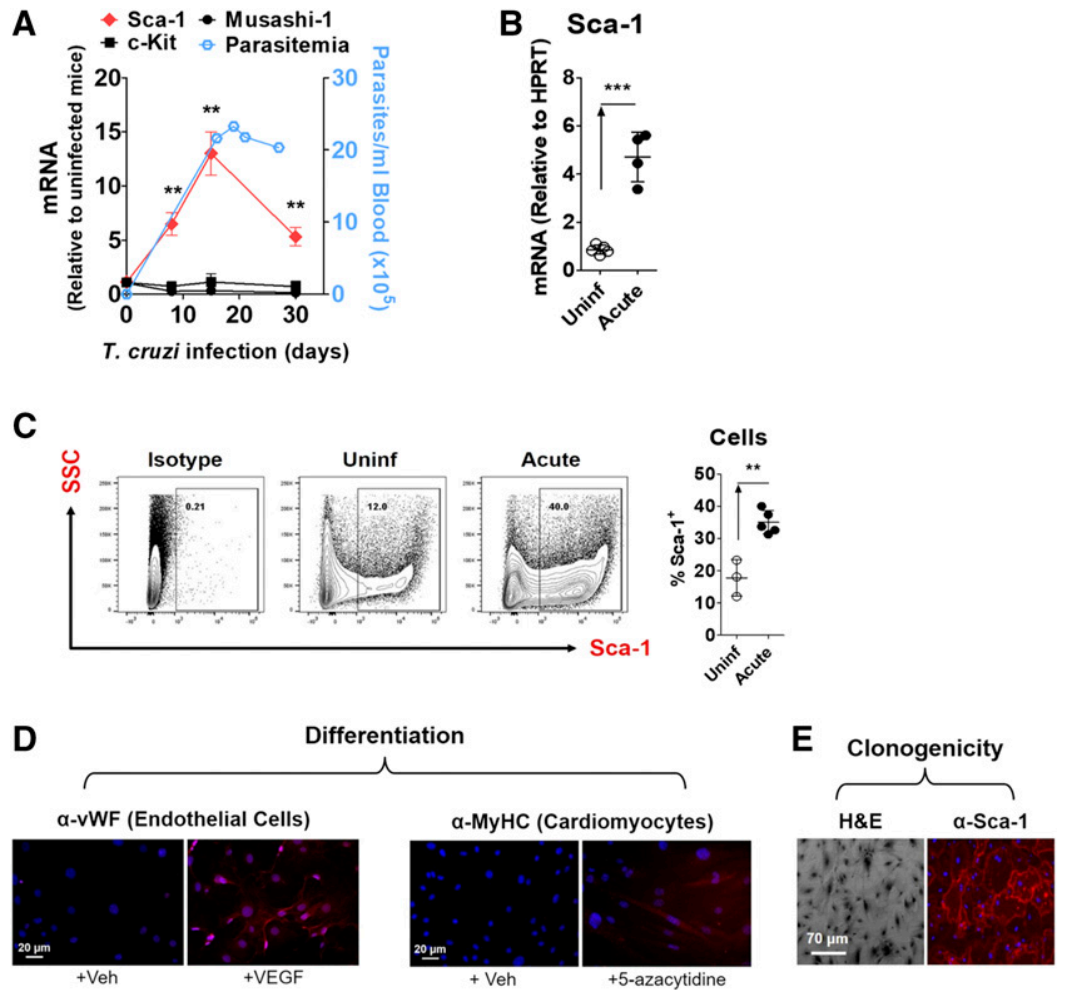

Fig. 1. Sca-1+ CPCs expand in the hearts of mice acutely infected with T. cruzi in a tissue parasitism-dependent manner. (A) Sca-1 transcript is preferentially elevated in the heart during acute $T$. cruzi infection in parallel with blood parasitemia. Mice were infected with $T$. cruzi by intraperitoneal injection and euthanized at the time points indicated. Left axis: Cardiac transcripts of stem-cell markers Sca-1, c-Kit, and Musashi-1 were quantified by quantitative PCR. Results are the mean \pm S.E.M. of fold-change expression relative to control mice $(n=3-5$ mice; two independent experiments). *** $P<$ 0.01. Right axis: Blood parasitemia over the course of acute T. cruzi infection was measured by optical microscopy. (B) Elevated Sca-1 transcript at the peak of acute $T$. cruzi infection indicates an expansion of the progenitor cell population. Mice infected with $T$. cruzi (Acute, $n=4$ ) express more cardiac Sca-1 mRNA than uninfected mice (Uninf, $n=5$ ). Mice were infected with 1000 parasites and euthanized 18 days later. Cardiac mRNA was quantified by quantitative PCR and plotted after normalization to hypoxanthine-guanine phosphoribosyltransferase. Results are the mean \pm S.D.; $* * * P<0.001$. $(\mathrm{C})$ An increased cardiac Sca-1 $1^{+}$progenitor cell population in acute T. cruzi infection mirrors the elevation in Sca-1 transcript. Mice were infected with 3000 parasites and euthanized 20 days later. Sca- $1^{+}$cells were quantified by flow cytometry. Results are the mean \pm S.D.; $* * P<0.01$. (D) Isolated Sca- $1^{+}$ cells can be reliably characterized as CPCs. Sca- $1^{+}$cells (passage 2) isolated from murine hearts were induced to differentiate into endothelial cells expressing von Willebrand factor (vWF) upon treatment with $20 \mathrm{ng} / \mathrm{ml} \mathrm{VEGF}$, or into cardiomyocytes expressing myosin heavy chain (MyHC) upon treatment with $10 \mathrm{mM} 5$-azacytidine. (E) Sca- $1^{+}$cells also exhibit clonogenicity, the ability to grow from a single cell into a colony. Representative image of a Sca- $1^{+}$colony expanded from a single cell plated by limiting dilution.

\section{Results}

Sca-1 ${ }^{+}$CPCs Expand in the Hearts of Mice Acutely Infected with $T$. cruzi in a Tissue ParasitismDependent Manner. To test the effects of $T$. cruzi infection on progenitor cell expansion in the heart, we measured transcripts of three known progenitor cell markers (Sca-1, c-kit, and Musashi-1) in heart tissues of mice over the course of acute infection with the Colombian strain of T. cruzi. We observed a significant increase in Sca-1 mRNA in infected mice relative to uninfected controls, with peak expression at 18 days PI (Fig. 1, A and B). The timing of this Sca-1 transcript elevation correlated with the established peak parasitism, as previously observed in this Chagas disease model of acute infection (Aridgides et al., 2013b), which suggests a causal relation between Sca-1 mRNA levels and the extent of cardiac tissue parasitism. In contrast, expression of markers c-kit and Musashi-1 were not affected by $T$. cruzi infection.

The increase in Sca-1 mRNA in acutely infected hearts reflected an expanded Sca- $1^{+}$cell population, as revealed by flow cytometry (Fig. 1C). Subsequent efforts were thus focused on $\mathrm{Sca}_{-} \mathrm{1}^{+}$cardiac progenitor cells (CPCs).
To verify that positive selection using the Sca-1 marker can reliably isolate a population of cardiac stem/progenitor cells, we isolated Sca- $1^{+}$cells from naïve mouse hearts by magneticactivated cell sorting and assessed them for stemness. In accordance with others' prior characterization of Sca- $1^{+}$heart cells (Oh et al., 2003; Smits et al., 2009; Ye et al., 2012; Valente et al., 2014), this population exhibited the potential to differentiate into defined phenotypes and the ability to expand from clones. Specifically, exposure to vascular endothelial growth factor induced expression of endothelial cell marker von Willebrand factor, and treatment with 5-azacytidine induced expression of cardiomyocyte lineage marker myosin heavy chain (Fig. 1D). The cells were also clonogenic, exhibiting the ability to grow into a colony from a single cell (Fig. 1E).

sPDNF Stimulates Expansion and Promotes Survival of CPCs In Vitro and In Vivo. To test the hypothesis that T. cruzi mediates stem-cell expansion via PDNF, we stimulated cardiac Sca $-1^{+}$CPCs with recombinant PDNF (sPDNF). We observed an exponential increase in the CPC population following sPDNF stimulation (Fig. 2A), a result reproduced in four other experiments (data not shown). 


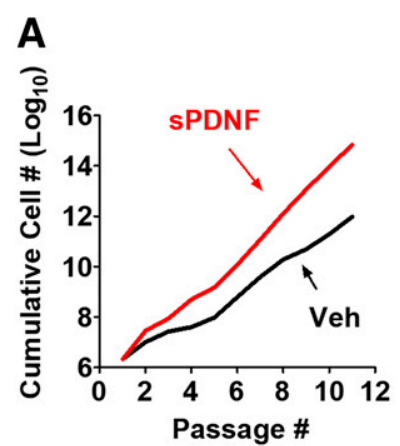

B

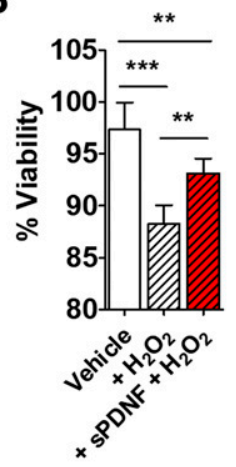

C

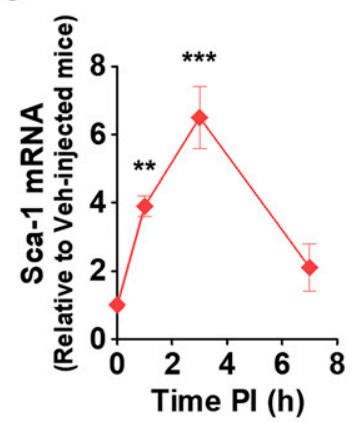

D

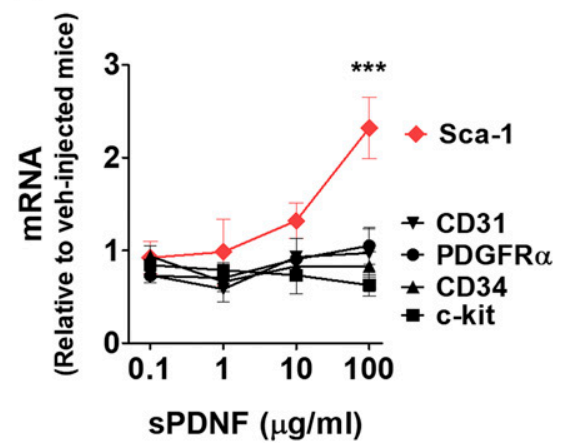

Fig. 2. sPDNF stimulates proliferation and survival of $\mathrm{CPCs}$ in vitro and in vivo. (A) SPDNF functions as a growth factor for CPCs in vitro. Cells were cultured in the presence or absence of $4 \mu \mathrm{g} / \mathrm{ml} \mathrm{sPDNF}$. Cell counts were recorded at each passage and summed for a cumulative cell number. (B) SPDNF preserves CPC viability in the presence of $\mathrm{H}_{2} \mathrm{O}_{2}$. CPCs were treated with $300 \mathrm{ng} / \mathrm{ml}$ sPDNF $\left(+\mathrm{SPDNF}+\mathrm{H}_{2} \mathrm{O}_{2}\right)$ or PBS vehicle $\left(+\mathrm{H}_{2} \mathrm{O}_{2}\right)$ for 30 minute prior to incubation with $\mathrm{H}_{2} \mathrm{O}_{2}$ or PBS vehicle (Vehicle) for 3.5 hours. Cell viability was assessed by quantitating percentage of cells not propidium iodide/Hoechst positive. Results are the mean \pm S.D.; $*_{*} P<0.01 ; * * * P<0.001$. (C) Intravenous sPDNF increases expression of cardiac Sca-1 mRNA. sPDNF ( $3 \mathrm{mg} / \mathrm{kg}$ ) administered to naïve mice $(n=3)$ resulted in higher levels of Sca-1 mRNA compared with vehicle-injected controls $(n=3)$. Results are the mean \pm S.D. of fold-change expression relative to control mice. $* * P<0.01 ; * * * P<0.001$. (D) Sca-1 mRNA is preferentially upregulated in a dose-dependent manner in the left ventricles of mice intravenously injected with sPDNF. Mice were injected with various doses of intravenous $\operatorname{SPDF}(n=2)$ or vehicle control $(n=2)$ and euthanized 3 hours postinjection. results are the mean \pm S.D. of fold-change expression relative to control mice. ${ }^{* * *} P<0.001$.
Our laboratory has previously shown that sPDNF protects cardiac cell populations (fibroblasts and myocytes) from death induced by oxidative stress (Aridgides et al., 2013a,b). Therefore, we examined the potential of
sPDNF to promote survival of Sca- $1^{+}$progenitor cells. As with the other cardiac cell types, sPDNF was able to protect CPCs from damage induced by oxidative stress (Fig. 2B).
A
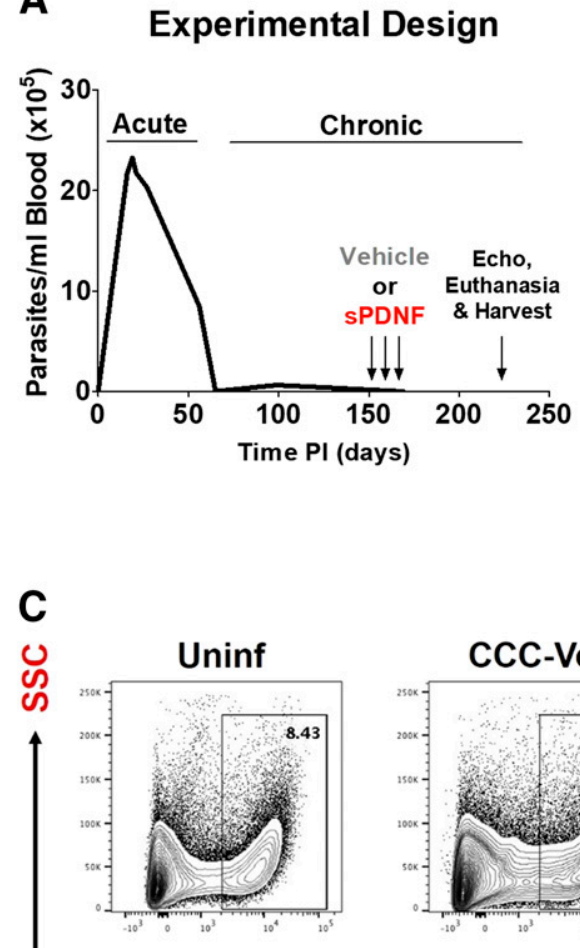
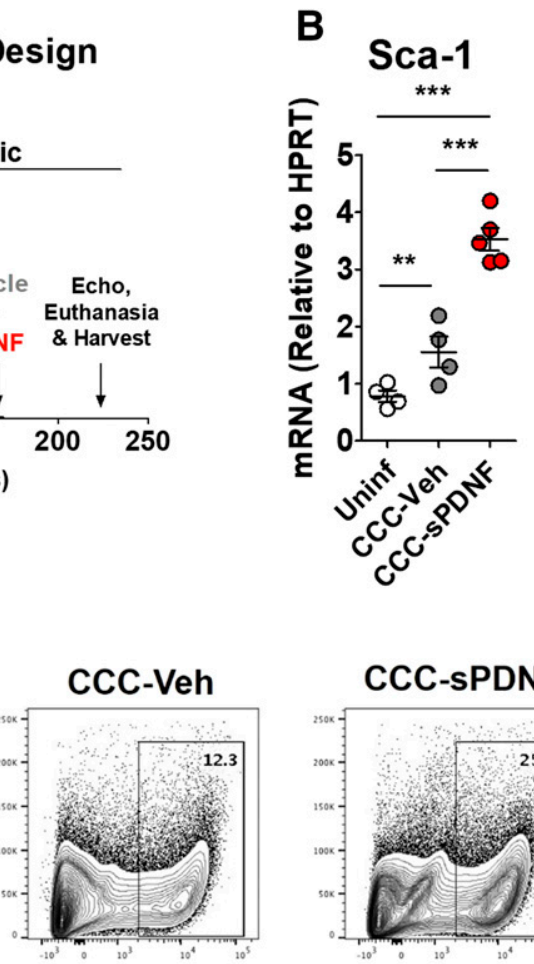

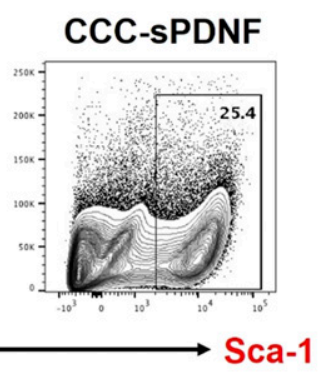

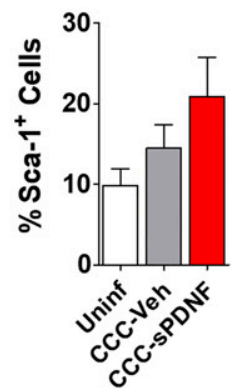

Fig. 3. Intravenous administration of sPDNF stimulates CPC proliferation in a mouse model of chronic Chagas cardiomyopathy. (A) Experimental protocol to test the effect of intravenous SPDNF in a mouse model of CCC. Female C57BL/6J mice were injected with Colombian T. cruzi (varying doses and routes of inoculation); age-matched controls (Uninf) were injected with PBS only. At 5 months postinjection, on days 150,157 , and 164 , mice were injected with $25 \mu \mathrm{g}$ intravenous sPDNF (3 mg/kg) (CCC-sPDNF) or $200 \mu \mathrm{l}$ PBS vehicle (CCC-Veh). Injections were performed at $T=0,3$, and 24 hours. Two months after final injection, on day 220 , mice underwent echocardiography (echo) prior to euthanasia and harvest. (B) Intravenous sPDNF augments Sca-1 transcript in the hearts of mice with experimental CCC. Sca-1 mRNA is significantly increased in CCC-sPDNF hearts compared with CCC-Veh or Uninf agematched controls $* * P<0.01 ; * * * P<$ 0.001. (C) An increased cardiac Sca- $1^{+}$ progenitor cell population in CCC mice receiving intravenous SPDNF reflects the elevation in Sca-1 transcript. CCC-sPDNF mice $(n=3)$ have a larger cardiac Sca- $1^{+}$cell population than uninfected mice $(n=2)$ or CCC-Veh $(n=3)$. Sca- $1^{+}$cells were quantified by flow cytometry. Results are the mean \pm S.D. 
To determine the in vivo relevance of the above in vitro observations, we next examined the effects of sPDNF on cardiac Sca-1 levels, as this would be relevant to the CPC growth we had observed with T. cruzi infection (Fig. 1, A and B). To determine whether intravenous sPDNF would upregulate Sca-1 mRNA, we injected naïve mice with SPDNF or PBS vehicle. SPDNF indeed induced a significant, selective, and dose-dependent increase in cardiac Sca-1 transcript, which peaked at 3 hours postinjection (Fig. 2, C and D). Transcripts of other stem-cell markers at the same time point were not affected by intravenous sPDNF (Fig. 2D), consistent with the results in acutely infected hearts (Fig. 1A).

Intravenous Administration of SPDNF Stimulates CPC Proliferation in a Mouse Model of CCC. In chronic Chagas cardiomyopathy, T. cruzi burden is so low that it is difficult to detect by optical microscopy (Fig. 3A). This implies that, in contrast to the acute infection period, tissue levels of PDNF in chronic infection may be, correspondingly, very low. We therefore tested whether augmentation of PDNF in chronic infection could alter the CCC phenotype. We specifically tested the effect of intravenous SPDNF administration in a mouse model of CCC. Five months after infecting C57BL/6J mice with $T$. cruzi, we administered intravenous SPDNF (3 $\mathrm{mg} / \mathrm{kg}$ ) weekly for 3 weeks, with doses given at $T=0,3$, and 24 hours.
Eight weeks after sPDNF injection, both Sca-1 mRNA and the proportion of Sca- $1^{+}$cells increased significantly in the hearts of CCC mice treated with SPDNF (CCCsPDNF) relative to CCC mice injected only with vehicle PBS (CCC-Veh), or to age-matched uninfected controls (Uninf) (Fig. 3, $\mathrm{B}$ and $\mathrm{C}$ ). This increase in cardiac Sca-1 mRNA in CCC-sPDNF mice correlates with the pattern of Sca-1 mRNA elevation observed in mice acutely infected with $T$. cruzi (Fig. 1B).

Intravenous SPDNF Decreases Cardiac T-Lymphocyte Infiltration in a Mouse Model of CCC. With evidence showing that SPDNF promotes survival and expansion of several different types of cardiac cells (Aridgides et al., 2013a,b), we investigated whether PDNF would affect cardiac pathology in chronically infected mice.

We first examined mononuclear cell infiltration, which is associated with cardiac damage and myocyte death (Morris et al., 1990; Milei et al., 1992; Reis et al., 1993). Immunohistochemistry (IHC) and flow cytometry identified a reduction in the levels of both $\mathrm{CD} 4^{+}$and $\mathrm{CD} 8^{+} \mathrm{T}$ cells in CCC-sPDNF hearts relative to the significantly increased infiltration observed in CCC-Veh (Fig. 4A). Flow cytometry corroborated the results of IHC, showing a reduction in T lymphocytes in the hearts of sPDNF-injected mice relative to control (Fig. 4B), though the difference was not statistically significant.
A
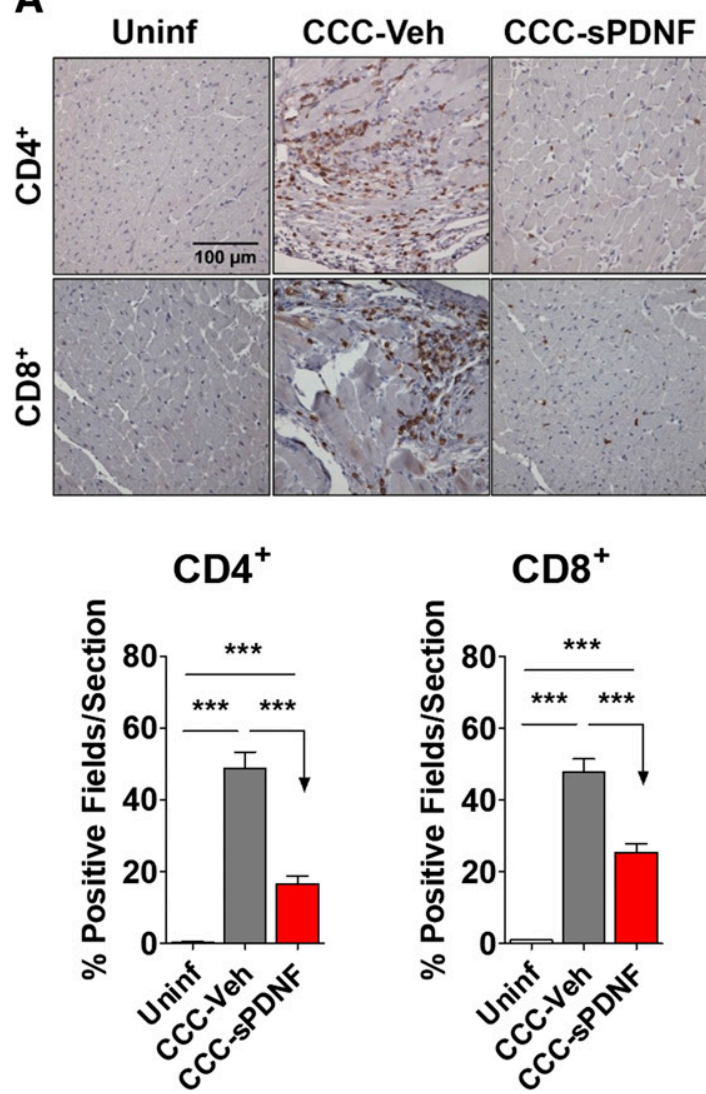

B

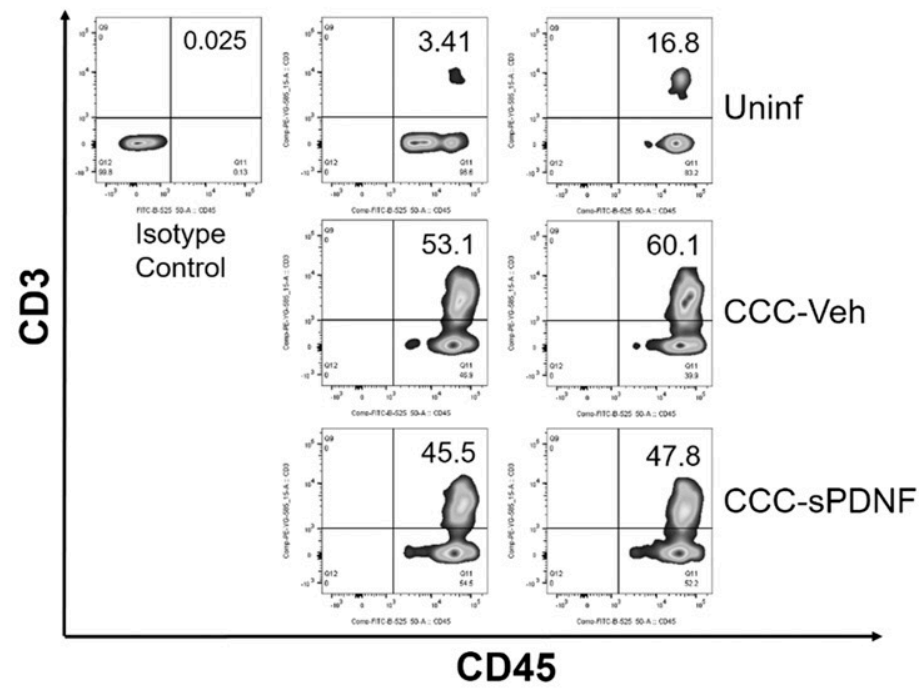

Fig. 4. Intravenous sPDNF decreases T-lymphocyte infiltration into the myocardium in a mouse model of chronic Chagas cardiomyopathy. (A) Intravenous SPDNF markedly reduces $\mathrm{CD} 4^{+}$and $\mathrm{CD} 8^{+} \mathrm{T}$-cell infiltration into the myocardium. sPDNF injection $(n=3)$ significantly reduced the number of infiltrating T cells relative to the focal inflammation seen in CCC-Veh $(n=2)$. Hearts were stained for CD $4^{+}$and CD8 ${ }^{+}$cells by immunohistochemistry. Quantification was performed using a grid overlay in ImageJ; positive squares (fields) within the grid were calculated as a percentage of all fields and averaged. ${ }^{* * *} P<0.001$. Results were repeated in a second mouse cohort. (B) $\mathrm{CD} 45^{+} / \mathrm{CD}^{+}$leukocytes are reduced in the hearts of in sPDNF-injected mice relative to vehicle controls. Whole-heart lysates were analyzed by flow cytometry. $n=2$ mice per group. 
A

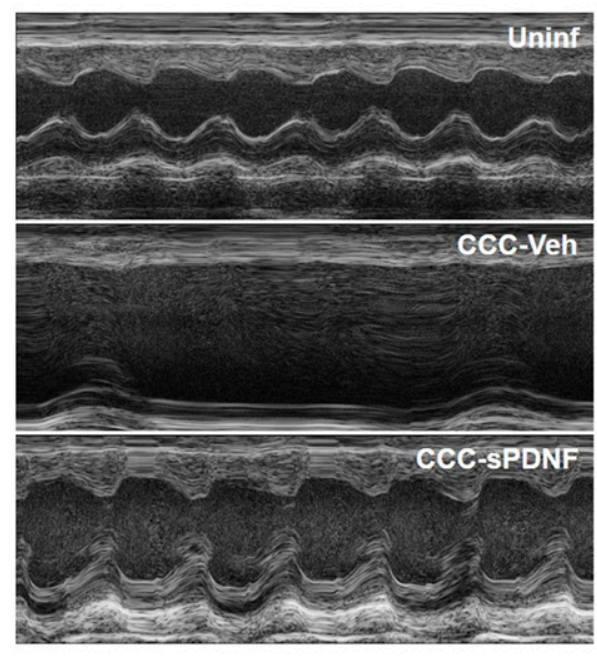

B

\section{End Diastolic Diameter}

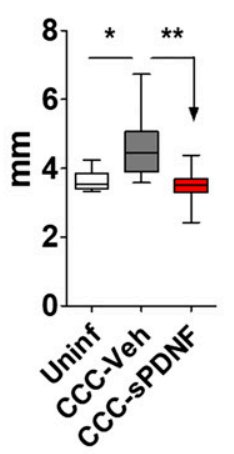

C

\section{End Systolic Diameter}

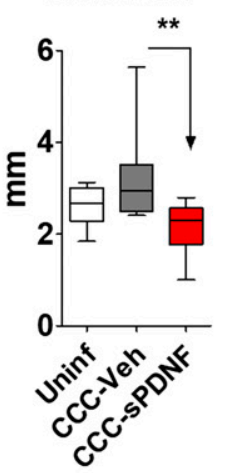

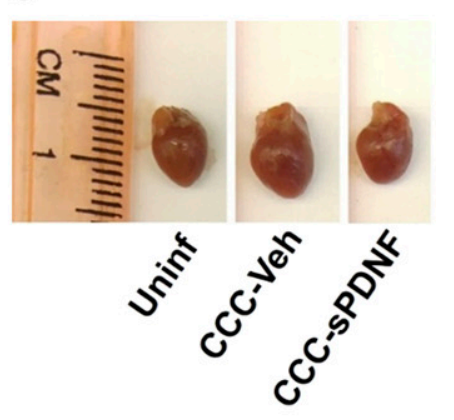

D

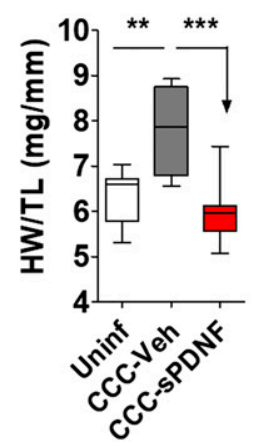

E

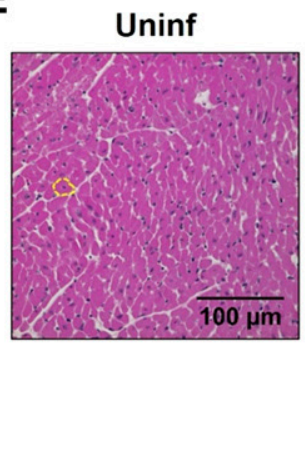

CCC-Veh

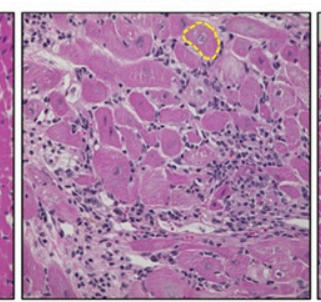

CCC-SPDNF

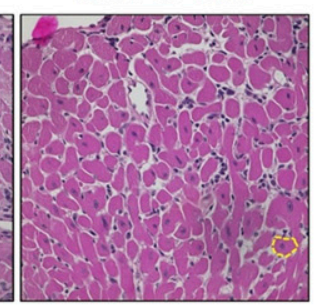

Cardiomyocytes

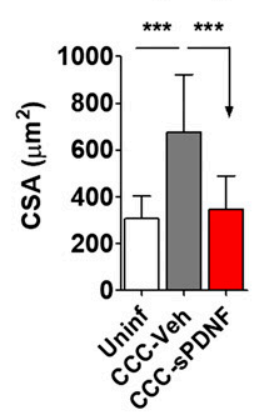

Fig. 5. Intravenous SPDNF reduces cardiac remodeling in a mouse model of chronic Chagas cardiomyopathy. Female C57BL/6J mice were infected with 1000 Colombian T. cruzi by intravenous injection and treated with sPDNF or vehicle control 5 months postinfection. (A) Representative m-mode echocardiograms from uninfected mice, mice with CCC receiving vehicle treatment (CCC-Veh), and CCC mice treated as in Fig. 3 with sPDNF (CCCsPDNF). (B) LV chamber size/dilation was assessed by echocardiography. Uninf, $n=9$; CCC-Veh, $n=8$; CCC-sPDNF, $n=10$. ${ }^{*} P<0.05$; $* * P<0.01$. Combined data from two independent experiments. (C) CCC mice receiving sPDNF treatment do not exhibit cardiac hypertrophy. Representative images of hearts excised from uninfected mice, CCC mice 8 weeks postinjection of sPDNF, and CCC mice 8 weeks postinjection of vehicle (CCC-Veh). (D) sPDNF injection reverses cardiac hypertrophy to levels of baseline Uninf. Hypertrophy was quantified by weighing the whole heart (heart weight, HW) and normalizing to tibia length (TL). $* * P<0.01 ; * * P<0.001$. (E) Intravenous sPDNF reduces cardiomyocyte cross-sectional area (CSA). Cardiac crosssections were stained with hematoxylin and eosin, and cardiomyocyte area was measured using SPOT Advanced software. Uninf, $n=3, \mathrm{CCC}-\mathrm{Veh}, n=2$, CCC-sPDNF, $n=3$. **** $P<0.001$.

The infiltration of other inflammatory cell populations, $\mathrm{CD} 11 \mathrm{~b}^{+}$macrophages and Gr-1 $1^{+}$neutrophils, was not significantly affected in chronically infected mice by either vehicle PBS or sPDNF injection (data not shown).

Intravenous sPDNF Reduces Cardiac Remodeling in a Mouse Model of CCC. An increased cardiac Sca- $1^{+}$ population is known to attenuate hypertrophy and fibrosis in a pressure-overload model of heart failure (Valente et al., 2014). We hypothesized that we would observe a similar amelioration of cardiac remodeling, including hypertrophy and chamber dilation, which are hallmark features of chronic Chagas disease (Morris et al., 1990; Rossi and Ramos, 1996).

We evaluated heart structure and function in CCC and agematched uninfected mice by echocardiography. Compared with uninfected mice, CCC-Veh mice developed increased left ventricular end-diastolic and systolic diameters, indicating chamber dilation. In contrast, CCC mice treated with sPDNF did not display a significant increase in LV diameter. Rather, chamber size in sPDNF-injected mice did not differ from Uninf controls (Fig. 5, A and B). Anterior and posterior wall thickness of the LV was not affected (Table 1). Gross examination of excised whole hearts from CCC mice revealed reduced size in sPDNF-treated CCC hearts compared with vehicle-treated CCC hearts (Fig. $5 \mathrm{C}$ ), corresponding to the echocardiographic chamber measurements. SPDNF effects on cardiac hypertrophy were also evident upon measurement of heart weight normalized to tibia length (HW/TL). Whereas CCC-Veh hearts had a significantly greater HW/TL ratio compared with Uninf, there was no difference between CCCsPDNF and Uninf (Fig. 5D). Likewise, the average crosssectional area of cardiomyocytes from CCC mice injected with sPDNF was significantly smaller than that of CCC-Veh mice (Fig. 5E).

Intravenous SPDNF Reduces Cardiac Fibrosis and Progression of Atrioventricular Block in a Mouse Model of CCC. Development of pathologic cardiac fibrosis represents an important feature of cardiac remodeling 
(Morris et al., 1990; Milei et al., 1992; Reis et al., 1993) and can be caused by myocardial T-cell infiltration (Ye et al., 2012; Hanif et al., 2017). Because intravenous sPDNF decreased lymphocyte infiltration and reversed left ventricular hypertrophy and dilation in the CCC mice, we investigated whether corresponding collagen buildup and fibrotic scarring would also be reduced. In contrast with the significantly elevated fibrosis seen in CCC-Veh, hearts from CCC mice injected with sPDNF showed no more fibrosis than those from Uninf (Fig. 6A).

Atrioventricular block, particularly right bundle branch block, is a classic manifestation of Chagasic cardiomyopathy (Elizari and Chiale, 1993). Electrocardiogram (ECG) revealed AV block in nearly all infected mice, ranging from mild PR interval prolongation to complete AV dissociation. Approximately 8 months PI-2 months after the end of the injection period-ECG demonstrated second- or third-degree AV block and corresponding bradycardia in all CCC mice injected only with vehicle (Fig. 6B; Table 2). However, the CCC mice that had received sPDNF were largely spared from severe conduction disturbances: Most exhibited only first-degree block, and some had completely normal ECG tracings (Fig. 6C). Heart rates were partially restored, as well, in CCC-sPDNF compared with CCC-Veh (Fig. 6B). This result was repeated in two cohorts of CCC mice, the combined results of which are given in Table 2 .

\section{Discussion}

In the present study, we provide evidence that a $T$. cruziderived, membrane-bound and shed protein, PDNF, promotes cardiac cell survival and expansion and ameliorates pathologic features of chronic Chagas disease. We observed: 1) increased myocardial proliferation of Sca- ${ }^{+}$CPCs in acute $T$. cruzi infection, but not in chronic infection; 2) sPDNF stimulation of the expansion of Sca- ${ }^{+}$CPCs both in vitro and in vivo; 3 ) reduction of myocardial leukocyte accumulation,
A

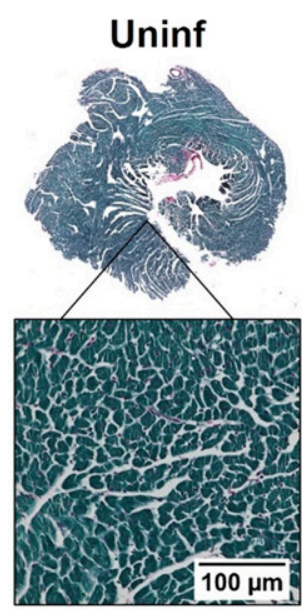

B

\section{Contractility Rate}

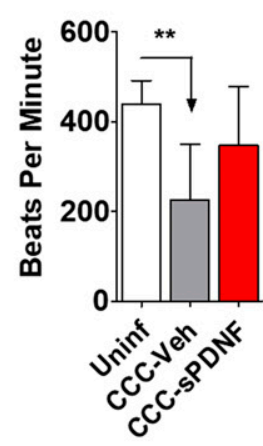

\section{CCC-SPDNF}
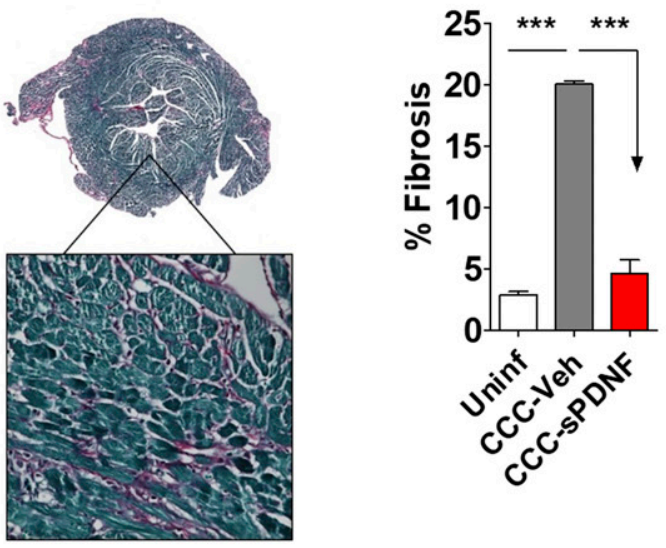

\section{CCC-Veh}

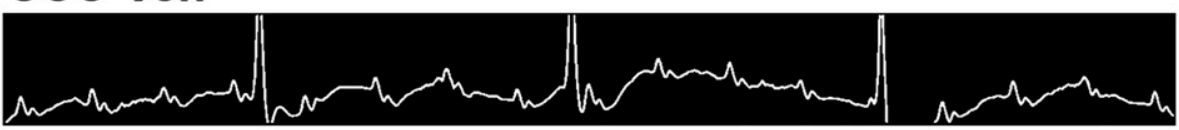

\section{CCC-sPDNF}

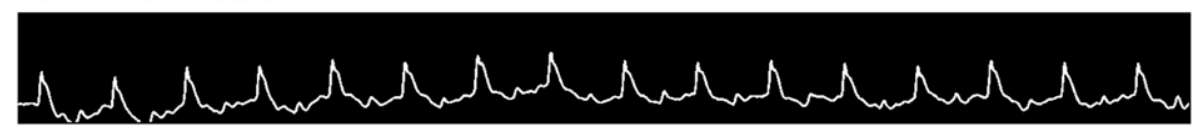

Fig. 6. SPDNF reduces cardiac fibrosis and progression of atrioventricular block in a mouse model of chronic Chagas cardiomyopathy. (A) Intravenous sPDNF substantially reduces fibrosis in CCC-sPDNF hearts relative to CCC-Veh. Mouse LVs were stained with Sirius Red (stains collagens) and Fast Green (stains noncollagenous proteins) for high-contrast visualization of fibrotic tissue. Whole-section stitched images were used to quantify percent fibrosis (percent red) using Keyence BZ-X Analyzer. Uninf, $n=3$; CCC-Veh, $n=2$; CCC-sPDNF, $n=3$. *** $P<0.001$. (B) sPDNF partially restores left ventricular contractility rate. Mice receiving sPDNF exhibited less severe left ventricular bradycardia than mice injected only with vehicle. Left ventricular heart rate was captured by echocardiography 8 weeks post-treatment. Uninf, $n=9$, CCC-Veh, $n=8$, CCC-sPDNF, $n=10$. *** $P<0.01$. (C) Intravenous SPDNF mitigates progression of AV block. Mice treated with sPDNF exhibited less severe AV block relative to CCC-Veh mice. Representative electrocardiograms 8 weeks post-treatment show normal tracing in Uninf, complete heart block in CCC-Veh, and first-degree block in CCC-sPDNF. 
TABLE 2

sPDNF mitigates progression of atrioventricular block

CCC-Veh, $n=7$; CCC-sPDNF, $n=10$.

\begin{tabular}{lcccc}
\hline & No Block (\%) & $1^{\circ}$ Block $(\%)$ & $2^{\circ}$ Block (\%) & $3^{\circ}$ Block $(\%)$ \\
\hline CCC-Veh & 0 & 0 & 29 & 71 \\
CCC-sPDNF & 20 & 40 & 10 & 30 \\
\hline
\end{tabular}

cardiac hypertrophy, and chamber dilation in CCC mice treated with SPDNF; and 4) SPDNF-induced improvement in characteristic Chagasic fibrosis and conduction abnormalities. We interpret our findings to indicate that SPDNF opposes the pathophysiologic features of CCC.

Our observation that Sca- $1^{+}$CPCs expand in acute $T$. cruzi infection may be relevant to the high survival rate, without sequelae, of acutely infected Chagasic patients (Marin-Neto et al., 2007; Rassi et al., 2010). As noted in other heart failure models, stem-cell proliferation contributes to cardiac repair (Valente et al., 2014) and may do so in several ways, either by differentiation and direct replacement of damaged tissue, or via activation by and of neighboring cells by paracrine signaling (Gnecchi et al., 2008). Conditioned medium from cultured stem cells, which contains growth and angiogenic factors, enable reverse remodeling and promotes cardiac regeneration. We thus interpret the stem-cell expansion within the broader context of cardiac repair after acute T. cruzi infection subsides. Further studies should make the role of CPCs clearer in SPDNF-mediated cardiac repair.

Likewise, data showing that SPDNF is capable of stimulating CPC expansion to a similar extent as T. cruzi suggests that this protein may be at least one of the factors mediating cardiac stem-cell growth, and that it may therefore be a factor influencing cardiac repair.

In reducing T-cell infiltration and pathologic ventricular remodeling, including hypertrophy and LV dilation, in CCC mice, sPDNF improves biomarkers that are prognostic indicators in human Chagas disease (Bocchi et al., 2017). T-lymphocyte infiltration into Chagasic myocardium has been well documented and shown to lead to destructive inflammatory conditions (Reis et al., 1993; Milei et al., 1996; Sanoja et al., 2013), which result in a worse prognosis for patients with CCC compared with patients with noninflammatory cardiomyopathies (Bocchi et al., 2017). Patients with Chagasic dilated cardiomyopathy also have a lower survival rate than those with idiopathic dilated cardiomyopathy (Pereira Nunes Mdo et al., 2010). That sPDNF improves these prognostic indicators suggests to us that it may merit further investigation as an eventual therapeutic strategy for CCC.

Hence, our findings support the idea that T. cruzi PDNF stimulates survival of cardiac stem cells, in addition to promoting survival of cardiac fibroblasts and myocytes (Aridgides et al., 2013a,b). It stands to reason that these PDNF actions on cardiac cells may help repair, in a mutually beneficial manner, myocardial damage caused by parasite invasion during and after acute infection. A corollary is that inexorable chronic cardiomyopathy, which develops despite low tissue parasitism, could be rescued with systemic administration of PDNF. The results presented here (Figs. 3-6) give credence to this new concept in T. cruzi invasion of the heart.

Aside from mechanistic considerations, our results could lead, in recombinant PDNF, to novel custom-made biologic therapeutics, with defined targets and effector functions, to enhance host-specific repair functions and selectively reduce $T$. cruzi burden in the heart, thereby rescuing deteriorated cardiac pathology and function in chronic Chagas heart disease. Additionally, exogenous PDNF administration might also be of therapeutic value in other types of degenerative cardiomyopathies unrelated to Chagas disease, highlighting the translational value of understanding pathogenesis mechanisms.

\section{Acknowledgments}

We thank Tania Nevers for assistance with flow cytometry and T-cell experiments, Francisco Velazquez for support with imaging and IHC quantification, Timothy Calamaras for help with echocardiography, and David Greenblatt for his insights during the writing of the manuscript.

\section{Authorship Contributions}

Participated in research design: Ledoux, Aridgides, Salvador, Ngwenyama, Perrin.

Conducted experiments: Ledoux, Aridgides, Salvador, Ngwenyama, Panagiotidou, Blanton.

Contributed new reagents or analytic tools: Alcaide, Blanton.

Performed data analysis: Ledoux, Aridgides, Salvador,

Ngwenyama.

Wrote or contributed to the writing of the manuscript: Ledoux, Aridgides, Perrin.

\section{References}

Aridgides D, Salvador R, and PereiraPerrin M (2013a) Trypanosoma cruzi highjacks TrkC to enter cardiomyocytes and cardiac fibroblasts while exploiting TrkA for cardioprotection against oxidative stress. Cell Microbiol 15:1357-1366.

Aridgides D, Salvador R, and PereiraPerrin M (2013b) Trypanosoma cruzi coaxes cardiac fibroblasts into preventing cardiomyocyte death by activating nerve growth factor receptor TrkA. PLoS One 8:e57450.

Bellotti G, Bocchi EA, de Moraes AV, Higuchi M L, Barbero-Marcial M, Sosa E, Esteves-Filho A, Kalil R, Weiss R, Jatene A, et al. (1996) In vivo detection of Trypanosoma cruzi antigens in hearts of patients with chronic Chagas' heart disease. Am Heart J 131:301-307.

Ben Younès-Chennoufi A, Hontebeyrie-Joskowicz M, Tricottet V, Eisen H, Reynes M, and Said G (1988) Persistence of Trypanosoma cruzi antigens in the inflammatory lesions of chronically infected mice. Trans $R$ Soc Trop Med Hyg 82:77-83.

Bern C (2015) Chagas' disease. N Engl J Med 373:456-466.

Blanton RM, Takimoto E, Lane AM, Aronovitz M, Piotrowski R, Karas RH, Kass DA, and Mendelsohn ME (2012) Protein kinase $\mathrm{g} i \alpha$ inhibits pressure overload-induced cardiac remodeling and is required for the cardioprotective effect of sildenafil in vivo. J Am Heart Assoc 1:e003731.

Bocchi EA, Bestetti RB, Scanavacca MI, Cunha Neto E, and Issa VS (2017) Chronic Chagas heart disease management: from etiology to cardiomyopathy treatment. $J$ Am Coll Cardiol 70:1510-1524.

Chuenkova MV, Furnari FB, Cavenee WK, and Pereira MA (2001) Trypanosoma cruzi trans-sialidase: a potent and specific survival factor for human Schwann cells by means of phosphatidylinositol 3-kinase/Akt signaling. Proc Natl Acad Sci USA 98:9936-9941.

Chuenkova M, Pereira M, and Taylor G (1999) trans-sialidase of Trypanosoma cruzi: location of galactose-binding site(s). Biochem Biophys Res Commun 262:549-556.

Chuenkova MV and Pereira MA (2000) A trypanosomal protein synergizes with the cytokines ciliary neurotrophic factor and leukemia inhibitory factor to prevent apoptosis of neuronal cells. Mol Biol Cell 11:1487-1498.

Chuenkova MV and Pereira MA (2003) PDNF, a human parasite-derived mimic of neurotrophic factors, prevents caspase activation, free radical formation, and death of dopaminergic cells exposed to the Parkinsonism-inducing neurotoxin MPP + . Brain Res Mol Brain Res 119:50-61.

Chuenkova MV and PereiraPerrin M (2004) Chagas' disease parasite promotes neuron survival and differentiation through TrkA nerve growth factor receptor. $J$ Neurochem 91:385-394.Cunha-Neto E, Coelho V, Guilherme L, Fiorelli A, Stolf N, and Kalil J (1996) Autoimmunity in Chagas' disease. Identification of cardiac myosin-B13 Trypanosoma cruzi protein crossreactive $\mathrm{T}$ cell clones in heart lesions of a chronic Chagas' cardiomyopathy patient. J Clin Invest 98:1709-1712.

Cunha-Neto E and Kalil J (1995) Autoimmunity in Chagas' heart disease. Sao Paulo Med J 113:757-766.

de Melo-Jorge M and PereiraPerrin M (2007) The Chagas' disease parasite Trypanosoma cruzi exploits nerve growth factor receptor TrkA to infect mammalian hosts. Cell Host Microbe 1:251-261.

Dias E, Laranja FS, Miranda A, and Nobrega G (1956) Chagas' disease; a clinical, epidemiologic, and pathologic study. Circulation 14:1035-1060.

Elizari MV and Chiale PA (1993) Cardiac arrhythmias in Chagas' heart disease. $J$ Cardiovasc Electrophysiol 4:596-608.

Gnecchi M, Zhang Z, Ni A, and Dzau VJ (2008) Paracrine mechanisms in adult stem cell signaling and therapy. Circ Res 103:1204-1219. 
Hanif W, Alex L, Su Y, Shinde AV, Russo I, Li N, and Frangogiannis NG (2017) Left atrial remodeling, hypertrophy, and fibrosis in mouse models of heart failure. Cardiovasc Pathol 30:27-37.

Köberle F (1968) Chagas' disease and Chagas' syndromes: the pathology of American trypanosomiasis. Adv Parasitol 6:63-116.

Lu B, Alroy J, Luquetti AO, and PereiraPerrin M (2008) Human autoantibodies specific for neurotrophin receptors TrkA, TrkB, and TrkC protect against lethal Trypanosoma cruzi infection in mice. Am J Pathol 173:1406-1414.

$\mathrm{Lu}$ B, Luquetti AO, Rassi A, and PereiraPerrin M (2010) Autoantibodies to neurotrophic receptors TrkA, TrkB and TrkC in patients with acute Chagas' disease. Scand J Immunol 71:220-225.

Machado FS, Dutra WO, Esper L, Gollob KJ, Teixeira MM, Factor SM, Weiss LM, Nagajyothi F, Tanowitz HB, and Garg NJ (2012) Current understanding of immunity to Trypanosoma cruzi infection and pathogenesis of Chagas disease. Semin Immunopathol 34:753-770.

Marin-Neto JA, Cunha-Neto E, Maciel BC, and Simões MV (2007) Pathogenesis of chronic Chagas heart disease. Circulation 115:1109-1123.

Melo MF, Moreira OC, Tenório P, Lorena V, Lorena-Rezende I, Júnior WO, Gomes Y, and Britto C (2015) Usefulness of real time PCR to quantify parasite load in serum samples from chronic Chagas disease patients. Parasit Vectors 8:154

Milei J, Fernández Alonso G, Vanzulli S, Storino R, Matturri L, and Rossi L (1996) Myocardial inflammatory infiltrate in human chronic chagasic cardiomyopathy: immunohistochemical findings. Cardiovasc Pathol 5:209-219.

Milei J, Storino R, Fernandez Alonso G, Beigelman R, Vanzulli S, and Ferrans VJ (1992) Endomyocardial biopsies in chronic chagasic cardiomyopathy. Immunohistochemical and ultrastructural findings. Cardiology 80:424-437.

Morris SA, Tanowitz HB, Wittner M, and Bilezikian JP (1990) Pathophysiological insights into the cardiomyopathy of Chagas' disease. Circulation 82:1900-1909.

Nevers T, Salvador AM, Velazquez F, Ngwenyama N, Carrillo-Salinas FJ, Aronovitz M, Blanton RM, and Alcaide P (2017) Th1 effector T cells selectively orchestrate cardiac fibrosis in nonischemic heart failure. J Exp Med 214:3311-3329.

Niu J and Kolattukudy PE (2009) Role of MCP-1 in cardiovascular disease: molecular mechanisms and clinical implications. Clin Sci (Lond) 117:95-109.

Nunes MCP, Dones W, Morillo CA, Encina JJ, and Ribeiro AL; Council on Chagas Disease of the Interamerican Society of Cardiology (2013) Chagas disease: an overview of clinical and epidemiological aspects. J Am Coll Cardiol 62:767-776.

Oh H, Bradfute SB, Gallardo TD, Nakamura T, Gaussin V, Mishina Y, Pocius J, Michael LH, Behringer RR, Garry DJ, et al. (2003) Cardiac progenitor cells from adult myocardium: homing, differentiation, and fusion after infarction. Proc Natl Acad Sci USA 100:12313-12318.

Palomino SAP, Aiello VD, and Higuchi ML (2000) Systematic mapping of hearts from chronic chagasic patients: the association between the occurrence of histopathological lesions and Trypanosoma cruzi antigens. Ann Trop Med Parasitol 94:571-579.

Parada H, Carrasco HA, Añez N, Fuenmayor C, and Inglessis I (1997) Cardiac involvement is a constant finding in acute Chagas' disease: a clinical, parasitological and histopathological study. Int $J$ Cardiol 60:49-54.

Parodi AJ, Pollevick GD, Mautner M, Buschiazzo A, Sanchez DO, and Frasch AC (1992) Identification of the gene(s) coding for the trans-sialidase of Trypanosoma cruzi. EMBO J 11:1705-1710.

Paucar R, Moreno-Viguri E, and Pérez-Silanes S (2016) Challenges in Chagas disease drug discovery: a review. Curr Med Chem 23:3154-3170.

Pereira ME (1983) A developmentally regulated neuraminidase activity in Trypanosoma cruzi. Science 219:1444-1446.

Pereira Nunes Mdo C, Barbosa MM, Ribeiro AL, Amorim Fenelon LM, and Rocha MO (2010) Predictors of mortality in patients with dilated cardiomyopathy: relevance of chagas disease as an etiological factor. Rev Esp Cardiol 63:788-797.
Pérez-Molina JA and Molina I (2018) Chagas disease. Lancet 391:82-94.

Prata A (2001) Clinical and epidemiological aspects of Chagas disease. Lancet Infect Dis 1:92-100.

Previato JO, Andrade AF, Pessolani MC, and Mendonça-Previato L (1985) Incorporation of sialic acid into Trypanosoma cruzi macromolecules. A proposal for a new metabolic route. Mol Biochem Parasitol 16:85-96.

Rassi A, Jr, Rassi A, and Marin-Neto JA (2010) Chagas disease. Lancet 375 1388-1402.

Reis DD, Jones EM, Tostes S, Jr, Lopes ER, Gazzinelli G, Colley DG, and McCurley TL (1993) Characterization of inflammatory infiltrates in chronic chagasic myocardial lesions: presence of tumor necrosis factor-alpha+ cells and dominance of granzyme A+, CD8+ lymphocytes. Am J Trop Med Hyg 48:637-644.

Rossi MA and Ramos SG (1996) Pathogenesis of chronic Chagas' myocarditis: an overview. Cardiovasc Pathol 5:197-202.

Salvador R, Aridgides D, and PereiraPerrin M (2014) Parasite-derived neurotrophic factor/trans-sialidase of Trypanosoma cruzi links neurotrophic signaling to cardiac innate immune response. Infect Immun 82:3687-3696.

Sanoja C, Carbajosa S, Fresno M, and Gironès N (2013) Analysis of the dynamics of infiltrating CD4(+) T cell subsets in the heart during experimental Trypanosoma cruzi infection. PLoS One 8:e65820.

Schenkman S, Pontes de Carvalho L, and Nussenzweig V (1992) Trypanosoma cruzi trans-sialidase and neuraminidase activities can be mediated by the same enzymes. J Exp Med 175:567-575.

Scudder P, Doom JP, Chuenkova M, Manger ID, and Pereira ME (1993) Enzymatic characterization of beta-D-galactoside alpha 2,3-trans-sialidase from Trypanosoma cruzi. J Biol Chem 268:9886-9891.

Smits AM, van Vliet P, Metz CH, Korfage T, Sluijter JP, Doevendans PA and Goumans M-J (2009) Human cardiomyocyte progenitor cells differentiate into functional mature cardiomyocytes: an in vitro model for studying human cardiac physiology and pathophysiology. Nat Protoc 4:232-243.

Soares MBP, Lima RS, Rocha LL, Takyia CM, Pontes-de-Carvalho L, de Carvalho AC, and Ribeiro-dos-Santos R (2004) Transplanted bone marrow cells repair heart tissue and reduce myocarditis in chronic chagasic mice. Am J Pathol 164: 441-447.

Tamura Y, Matsumura K, Sano M, Tabata H, Kimura K, Ieda M, Arai T, Ohno Y, Kanazawa H, Yuasa S, et al. (2011) Neural crest-derived stem cells migrate and differentiate into cardiomyocytes after myocardial infarction. Arterioscler Thromb Vasc Biol 31:582-589.

Tarleton RL and Zhang L (1999) Chagas disease etiology: autoimmunity or parasite persistence? Parasitol Today 15:94-99.

Valente M, Nascimento DS, Cumano A, and Pinto-do-Ó P (2014) Sca-1+ cardiac progenitor cells and heart-making: a critical synopsis. Stem Cells Dev 23: $2263-2273$

Weinkauf C, Salvador R, and Pereiraperrin M (2011) Neurotrophin receptor TrkC is an entry receptor for Trypanosoma cruzi in neural, glial, and epithelial cells. Infect Immun 79:4081-4087.

Ye J, Boyle A, Shih H, Sievers RE, Zhang Y, Prasad M, Su H, Zhou Y, Grossman W, Bernstein HS, et al. (2012) Sca-1+ cardiosphere-derived cells are enriched for Isl1expressing cardiac precursors and improve cardiac function after myocardial injury. PLoS One 7:e30329.

Address correspondence to: Dr. Mercio Perrin, Tufts University School of Medicine, Department of Developmental, Molecular and Chemical Biology, 150 Harrison Avenue, Boston, MA 02111. E-mail: Mercio.Perrin@tufts.edu 